\title{
MEASUREMENT METHODS AND STANDARDS FOR PROCESSING AND \\ APPLICATION OF THERMAL BARRIER COATINGS
}

\author{
S.J. Dapkunas \\ National Institute of Standards and Technology \\ Gaithersburg, Maryland
}

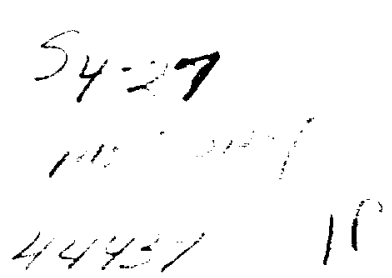

Application of thermal barrier coatings deposited by thermal spray, physical vapor and possibly other methods is expected to be extended from aircraft gas turbines to industrial and utility gas turbines as well as diesel engines. This increased usage implies the participation of greater numbers of processors and users, making the availability of standards for process control and property measurement more important. Available standards for processing and evaluation of thermal barrier coatings are identified as well as those needed in the future but currently unavailable.

PRECEDING PAGE BLANK NOT FILMEX? 